\title{
Consumers on the Internet: ethical and legal aspects of commercialization of personalized nutrition
}

\author{
Jennie Ahlgren • Anders Nordgren • Maud Perrudin • Amber Ronteltap • \\ Jean Savigny · Hans van Trijp · Karin Nordström · Ulf Görman
}

Received: 15 November 2012/ Accepted: 12 January 2013/Published online: 8 March 2013

(C) Springer-Verlag Berlin Heidelberg 2013

\begin{abstract}
Consumers often have a positive attitude to the option of receiving personalized nutrition advice based upon genetic testing, since the prospect of enhancing or maintaining one's health can be perceived as empowering. Current direct-to-consumer services over the Internet, however, suffer from a questionable level of truthfulness and consumer protection, in addition to an imbalance between far-reaching promises and contrasting disclaimers. Psychological and behavioral studies indicate that consumer acceptance of a new technology is primarily explained by the end user's rational and emotional interpretation as well as moral beliefs. Results from such studies indicate that personalized nutrition must create true value for the consumer. Also, the freedom to choose is crucial for
\end{abstract}

This study was conducted on behalf of the Food4Me project. Food4Me is the acronym of the EU FP7 project: "Personalised nutrition: an integrated analysis of opportunities and challenges" (Contract no. KBBE.2010.2.3-02, Project no. 265494). The Parties of the project are listed on the Web site of the project,

http://www.food4me.org/. The project co-ordination was carried out at University College Dublin, Ireland, Institute of Food and Health; Project Coordinator: Professor Michael J Gibney, Project Manager: Dr. Marianne Walsh. For overall correspondence regarding the Food4Me project: Professor Michael J Gibney, UCD Institute of Food and Health, University College Dublin, Dublin, Ireland,

Tel: +353-1-716-2824, Mail: mike.gibney@ucd.ie.

\section{J. Ahlgren $(\bowtie) \cdot$ U. Görman}

Ethics Unit, Centre for Theology and Religious Studies,

Lund University, Lund, Sweden

e-mail: jennie.ahlgren@teol.lu.se

\section{A. Nordgren}

Centre for Applied Ethics, Linköping University,

Linköping, Sweden

M. Perrudin · J. Savigny

Keller and Heckman LLP, Brussels, Belgium consumer acceptance. From an ethical point of view, consumer protection is crucial, and caution must be exercised when putting nutrigenomic-based tests and advice services on the market. Current Internet offerings appear to reveal a need to further guaranty legal certainty by ensuring privacy, consumer protection and safety. Personalized nutrition services are on the borderline between nutrition and medicine. Current regulation of this area is incomplete and undergoing development. This situation entails the necessity for carefully assessing and developing existing rules that safeguard fundamental rights and data protection while taking into account the sensitivity of data, the risks posed by each step in their processing, and sufficient guarantees for consumers against potential misuse.

Keywords Personalized nutrition - Direct-to-consumer . Nutrigenomic tests · Attitudes · Consumer acceptance · Ethics $\cdot$ Legal regulation

\section{Introduction}

The prospect of using nutrigenomics science for personalized nutritional advice based upon individual genetic information appears to be commercially attractive-as

\footnotetext{
A. Ronteltap

LEI, Wageningen University and Research Centre,

Wageningen, The Netherlands

H. van Trijp

Marketing and Consumer Behaviour, Group Wageningen

University and Research Centre, Wageningen, The Netherlands

K. Nordström · U. Görman

School of Education and Communication, Jönköping University, Jönköping, Sweden
} 
indicated by the emergence of companies offering such services. Personalized nutrition fits into an ongoing marketing trend in which consumer-supplier relationships increasingly move from a commodity model toward a personalized model. Public attitudes to new technologies are among the most important factors that determine the successful implementation of any technology (Sjöberg 2005), and personalized nutrition is no exception.

Nutrigenomics is a relatively young scientific field, and it is surrounded by considerable uncertainty regarding its actual deliverables for health improvement (see Görman et al. 2012 this issue). Because of this, efforts in using nutrigenomics to offer individual tailor-made nutritional advice raise a number of questions. In this paper, we review some of the most crucial ethical and legal concerns related to the commercialization of personalized nutrition advice based on genetic information. We identify such concerns primarily with respect to consumers using the Internet.

\section{Consumer attitudes}

Several studies indicate that the European public often holds a positive attitude toward genetic testing and personalized nutrition. In a pan-European study into consumer attitudes toward genetic testing and personalized nutrition, $66 \%$ of the respondents stated that they would be willing to undergo a genetic test and $27 \%$ would be willing to follow a personalized diet. Those who were willing to undergo a genetic test for personalized advice more often had high blood cholesterol, obesity, and high stress levels than those willing to take a genetic test out of general interest. Respondents who were unwilling to take a genetic test were more often male and less often obese. Those who were aware of health problems related to the metabolic syndrome were particularly in favor of receiving personalized dietary advice (Stewart-Knox et al. 2009).

A questionnaire study conducted in Sweden also revealed interest in the use of personalized nutrition services. Here, $70 \%$ of respondents declared that they would be willing to undergo a genetic test in order to receive such nutritional advice. Among the respondents, $65 \%$ stated that they would be willing to have their under-age children tested (Ahlgren, in prep). More often than older respondents (aged 46-79 years), younger ones (aged 16-45 years) indicated that they were interested in personalized nutritional advice based on genetic tests. In contrast to the results of the above study by Stewart-Knox et al., this willingness did not correlate with any kind of self-reported health problems $(77 \%$ of subjects described their health as good or very good). Clearly, if personalized dietary advice is to have any positive effect for the consumer, they will actually have to follow the advice given. In the Ahlgren study, $65 \%$ of the respondents asserted that they would follow such personalized advice, whereas $20 \%$ said that their willingness was dependent on the likelihood or unlikelihood of developing any serious disease if the advice was not followed (Ahlgren, in prep.). This could be taken to mean that known disease risks may motivate respondents to follow dietary advice.

An interview study, using informants sampled from the above Swedish questionnaire study, confirmed the initial quantitative results. In the interview study, informants were asked about the reasons and motives underlying their willingness (or unwillingness) to make use of nutrigenomic services. As anticipated, the informants made it clear that good health was of great value to them and what they expected from personalized dietary advice was personal empowerment in relation to their health. Informants also stressed the fact that relatives, for example, children and siblings, could benefit from the results and the advice given (Ahlgren, in prep.). In addition to the results from StewartKnox et al., these findings indicate that a feeling of personal relevance contributes to a positive attitude toward nutrigenomics-based personalized nutrition.

Although respondents and informants in the Swedish studies displayed a positive attitude toward gene-based personalized dietary advice, they also expressed some concerns regarding ethical matters. In the questionnaire study, $63 \%$ of respondents were concerned that genetic information might end up in the wrong hands, for example, with insurance companies or employers (Ahlgren, in prep.; Chadwick 2004). Such concerns call for a well-defined legal framework regarding not only the collection of genetic data, but also the storage of both DNA and information based on such data. Another identified area of ethical apprehension was related to legal aspects. Who may benefit from these nutrigenomic services? At present, such services are not available for everyone, partly owing to economic factors (Ahlgren, in prep.). Wendel et al. (2009) identify an additional ethical concern raised by consumers. Results from their study indicate that consumers are wary of commercial interests, as exemplified by the following areas of disapproval: branded personalized nutrition; commercial ownership of database technology that translates a consumer's profile into personalized nutritional advice; and commercial fitness clubs offering personalized nutrition.

Thus, good health is of great importance to consumers, and the opportunity for self-managed health appears to have appeal and is perceived as empowering despite some concerns regarding ethical and legal matters and fears. Even at the early stage of investigating the connection between genotypes and responses to dietary factors, it was foreseen that such knowledge might be used to provide 
individual, tailor-made nutritional advice. It was understood that this might raise consumer interest and create business opportunities.

\section{Personalized nutrition services on the internet}

Over the last decade, a substantial number of Internet companies have offered personalized information based upon individual DNA (Ronteltap et al. 2012). Not all of these companies offer health-related information. Other services that may be offered include paternity testing, genetic ancestry testing, and testing for such matters as the probability of baldness and sensitivity to bitter tastes. In addition, among the health-focused companies, not all are concerned with providing consumers with advice concerning eating and lifestyle habits. Another important branch is pharmacogenetics, which is not addressed in the present paper. However, a few companies-albeit fewer than some years ago-offer nutrigenomic testing.

The activities of online nutrigenomic companies have been subjected to strong criticism, not least from the US Government Accountability Office, which questions the utility of nutrigenomic tests and personalized advice. It states that the companies it has investigated mislead consumers by offering them health-related information that is meaningless, and predictions that are medically unproven (US Government Accountability Office 2006, 2010).

In spite of such criticism, many companies still offer DNA information on a direct-to-consumer (DTC) basis over the Internet. They often achieve this by using a variety of rhetorical tools. Several of them promise practical benefits and use prestigious words indicative of strong health benefits. In particular, it is common to appeal to "empowerment" and "identity" (Nordgren and Juengst 2009; Nordgren 2012)—concepts that are potentially appealing to consumers. DNA information is said to empower the individual, that is, help them take control over their own health by providing access to genetic information and stimulating them to take medical or preventive measures. Some examples illustrate this point:

Navigenics is the leading provider of clinically guided genetic analysis. Our goal is to empower you with genetic insights to help motivate you to improve your health. We also put a premium on privacy, keeping you in control of your genetic information. (Navigenics 2011).

Getting to know your personal genome will empower you and provide you with a road map to improve your health. (deCODEme 2011).
Some companies also appeal to identity or the customer's self-image. In their appeal to personal identity, the companies stress that DNA information provides knowledge pertinent to it. Two examples illustrate this:

You are unique. That's exactly why your personal genetic test from Inherent Health is such a valuable step towards a life time of good health. The genetic tests offer personalized guidance for consumers looking for evidence-based insights on how their genes may impact their health and wellness. (Interleukin 2011).

By tapping into advances in DNA analysis and offering education, tools, and expertise, we at 23andMe want to help others take a bold, informed step toward self-knowledge. (23andMe 2011).

Given that the resulting information is correct and relevant, nutrigenomic tests may be useful for consumers. In the debate concerning health-related DNA DTC testing, the key arguments in favor of nutrigenomic DTC testing are as follows: (1) Nutrigenomic DTC testing may help individuals find a diet that matches their genes and fulfills their nutritional needs, thereby improving their health; (2) It may help people find more efficient ways of reducing their weight, for example, focusing on carbohydrates rather than fat or vice versa. The arguments against such testing include the following: (1) Nutrigenomic tests are scientifically unvalidated, inadequate, and premature; (2) There is a risk of misinterpreting test results. With some exceptions, Internet companies offer no genetic counseling, which augments the risk of misinterpretation; (3) The information is much less instructive than the companies indicate. Often the consumer is merely offered common sense advice, such as that they should quit smoking, exercise, and eat fewer unhealthy foods. In addition, some companies' disclaimers make it clear that there are limitations to what should be expected. Some examples illustrate this:

The Genetic Scan product is for informational purposes only, is not medical advice, and is not a substitute for professional medical advice, genetic counseling, diagnosis, or treatment. You must seek the advice of your physician or other qualified health provider with any questions you may have regarding the genetic aspects of a medical matter and you must not disregard professional medical advice or delay seeking it because of the results of your Genetic Scan or anything you have read on the deCODEme Site. (deCODEme 2011).

The Services provided by Interleukin are solely for research and educational purposes and uses. Although based on scientific research, the Services, including 
all information about genetic findings and probabilities, shall not be relied upon by you or any other person to diagnose, treat or prevent any disease or health condition... We do not warrant the accuracy, effectiveness and suitability of this information. (Interleukin 2011).

Unless the consumer reads and understands the fine print, this imbalance between far-reaching promises of empowerment and the contrasting disclaimers may pose a problem. It is thus clear that there is a need for legal regulation of nutrigenomic genetic testing (Nordgren 2012).

Although current knowledge about the interaction between individual genotype, metabolism, and health is still fragmentary, nutrigenetic analysis of a gene test can in certain limited cases make it possible to provide consumers with information about individual health risks (see Görman et al. 2012 this issue). Such information may motivate the individual to change their dietary habits and lifestyle for the better. However, the possible gain rests on the level of accuracy and consumer security throughout the process of personalized nutrition services. This ethically complex situation calls for action to safeguard the consumer. Though nutrigenomic products are already on the market, the results of nutrigenomic research and the possibilities for evidencebased personalized advice are still at an immature stage. The need for legal regulation is thus of particular significance.

\section{Consumers and new technologies}

In a conceptual framework for consumer acceptance of technology-based food innovation, characteristics of the technology, the consumer, and the social system together influence the consumer's willingness to accept that technology. These characteristics trigger one or more psychological processes, for example, a rational trade-off between a technology's benefits and costs, or more emotional perceptions of risk and uncertainty. The means of communication influence which of the characteristics and which of the psychological processes have the strongest influence on consumer acceptance. Hence, acceptance is primarily explained by the end users' interpretation of the technology, including their moral beliefs about it (Ronteltap et al. 2007; Sjöberg 2005). In the case of nutrigenomics, studies indicate that it would be beneficial for public acceptance if expert stakeholders were to communicate unanimously about the technology, if the actual spin-off products provided clearly recognizable advantages to the consumer, and if the technology could be easily implemented in daily life. Public acceptance is particularly enhanced if the consumer has the freedom to choose whether or not he wishes to make his genetic profile available (Ronteltap et al. 2009).
Results from the above consumer studies indicate a few key issues. Personalized nutrition must create true value for the consumer one way or another. Consumers will critically evaluate personalized nutrition on the basis of perceived benefits to them-either direct benefits that accrue to the consumer personally or indirect benefits for another group in society. Also, the freedom to choose whether or not to use nutrigenomic genetic testing-instead of being forced into it or tempted by deceitful means-is crucial for consumer acceptance. Taking into account consumers' hesitance toward commercial interests and questions about genetic data samples and information, it is clear that some caution must be exercised when putting nutrigenomicbased tests and advice services on the market. That is even more pertinent if we realize that for companies to be profitable, a certain degree of customer lock-in is requisite. Finding the optimal solution to this potential disparity is a task for those studying or promoting the further development of nutrigenomics-based personalized nutrition.

\section{Legal aspects of personalized nutrition}

Irrespective of whether the commercial offering is made on the Internet, personalized nutrition is not currently subject to specific legal regulations. At the same time, although business models for personalized nutrition offerings are still, by and large, under development, current Internet services (Ronteltap et al. 2012) already appear to reveal a need to further guaranty legal certainty by ensuring privacy and the highest standards of consumer protection and safety. Three steps in delivering personalized nutrition products particularly require attention from a legal perspective: (1) gathering personal information from the consumer; (2) using the consumer's data to (automatically) generate personalized nutrition advice based on validated algorithms; and (3) providing advice to the consumer. This is obviously even more essential when the contact between the consumer and the personalized nutrition provider is conducted by means of the Internet (via the provider's Web site or via e-mail) throughout the process.

The extent of the legal implications of personalized nutrition always depends on the stated purpose of the personalized nutrition service offered, the legal status of the provider, and the health status of the consumer. The typical purpose of current offerings is to provide consumers with personalized dietary or lifestyle advice (e.g., a proposed recipe database, exercise regimes) based on selfreported food-intake data (level 1), taking phenotype (level 2), or phenotype and genotype (level 3) into account. Arguably, guiding consumers' decision about diet or exercise on the basis of measured polymorphism (levels 2 and 3) aims at participating in the prevention and treatment 
of certain diseases. Therefore, although no medical practitioner or health-care provider need be directly involved in the final personalized nutrition-delivering process, this type of DTC business activity might be construed as pursuing a medical objective, depending on the state of health of the consumer. Rather than questionable disclaimers limiting the liability of personalized nutrition advice providers regarding the effect of such advice on the health of their clients, the prerequisite for any personalized nutrition offered to consumers by non-medical professionals should arguably be as follows: compliance with clear criteria and targeting various groups of consumers while taking into account their state of health (e.g., no medical supervision needed).

DTC testing devices ${ }^{1}$

Although not specific to personalized nutrition, two directives of the European Union (EU) appear to be of particular relevance: the Medical Diagnostic Devices Directive (MDD) (MDD 1993) and the In Vitro Diagnostic Devices Directive (IVDD) (IVDD 1998). Applying a broad interpretation of their scope to include tests carried out in the context of "lifestyle services," such as personalized nutrition, whether DTC tests are subject to pre-market conformity assessment depends on the degree of risk associated with their use (Human Genetics Commission 2003). Though DNA tests for medical purposes are clearly covered by the current version of the IVDD, the situation remains unclear with regard to DNA DTC tests for lifestyle purposes.

This weakness in implementing the IVDD has become evident since 2000. Its classification system has become inadequate for the new in vitro diagnostic services. Ongoing revision of the IVDD by the European Commission (public consultation by the European Commission ${ }^{2}$ ) clearly intends to clarify the situation and to subject in vitro diagnostic services to additional requirements related to such issues as safety and quality. That being said, the issue of the analytic or clinical validity and clinical utility of DTC self-testing (including DNA testing) in the context of

\footnotetext{
${ }^{1}$ DTC testing services involve obtaining (via post) consumers' genetic information from blood samples (using, e.g., kits for thumb pricking) and buccal cells (using, e.g., kits to take buccal swabs) for checking DNA DTC testing.

${ }^{2}$ Public Consultation by the European Commission, Health and Consumers Directorate-General on the Revision of Directive 98/79/ EC of the European Parliament and of the Council of October 27, 1998, on in vitro diagnostic medical devices: (1) Questionnaire, June 2010, http://ec.europa.eu/enterprise/newsroom/cf/itemdetail.cfm?item_ id=4404. (2) Summary of responses, February 2011, http://ec .europa.eu/health/medical-devices/files/recast_docs_2008/ivd_pc_out come_en.pdf.
}

lifestyle services will very likely be quite difficult to address.

\section{Consumers' personal data}

The Charter of Fundamental Rights of the European Union recognizes in its Article 8 the right to the protection of personal data (Charter of Fundamental Rights of the European Union 2010). The Data Protection Directive and the E-Privacy Directive specify a number of requirements, exceptions, and safeguards relating to confidentiality and security that interactive online services have to meet in order to lawfully process sensitive data related to health in the EU market (Data Protections Directive 1995; Proposal for a General Data Protection Regulation 2012; Directive on Privacy and Electronic Communications 2002). They also prescribe sanctions and appropriate remedies in cases of breach and establish enforcement mechanisms to make those requirements effective.

Security and privacy-enhancing technologies appear to offer an additional tool to ensure personal data protection when personal data are disseminated through information and communication technologies networks and the processing of data crosses several jurisdictions (Communication on PETs 2007).

The processing of consumers' personal data related to health within the framework of commercial DTC relationships entails the necessity of a careful assessment of the existing rules safeguarding fundamental rights and data protection. This has to be evaluated in terms of the existing solutions offered by information technology (today and in the foreseeable future) to detect possible dangers leading to the determination of whether specific legislation is needed.

The sensitivity of data related to health is recognized by existing legislation. But—are the applicable requirements appropriate in the context of DTC services that do not involve health-care professionals subject to legal obligations of professional secrecy? Do the applicable requirements address all the risks posed by the particular sensitivity of genetic information at each step of their processing-collection, access, disclosure, storage, and circulation? Do applicable requirements provide sufficient guarantees for consumers against potential misuse or abuse?

\section{Personalized nutrition advice service}

The typical current offerings-personalized dietary or lifestyle advice provided to consumers by self-employed economic operators for remuneration-should arguably be regarded as a service covered by Directive 2006/123/EC on services (Services Directive 2006). This is in contrast with health-care services provided by health professionals to 
patients since these services are excluded from the scope of that directive. Moreover, like any service provided for remuneration at a distance, by electronic means, and at the individual request of the recipient, any such personalized nutrition service is also regulated by Directive 2000/31/EC (Directive on Electronic Commerce 2000). With regard to commercial communications, the EU horizontal laws governing the misleading promotion of services equally apply to lifestyle services, such as those for personalized nutrition (Misleading and Comparative Advertising Directive 2006; Unfair Commercial Practices Directive 2005).

Taking into account their purpose (lifestyle services), the nature of DTC tests required for obtaining genetic information and the sensitive nature of that information, personalized nutrition services are on the borderline between nutrition and medicine. In our ongoing assessment of whether the consumer, although not a patient, can be assured of the highest quality of lifestyle offerings based on genetic information and also be ensured privacy everywhere in the EU, the current developments in the ehealth area at the EU level in the context of the eHealth action plan (eHAP) 2012-2020 need to be closely monitored. ${ }^{3}$

\section{Conclusions}

Despite some concerns, consumers often have a positive attitude to the option of receiving personalized nutrition advice based on genetic testing. An important reason for this seems to be the value of good health and, consequently, the prospect of enhancing or maintaining one's own health can be perceived as empowering. Current Internet services for delivering individual DTC advice based on lifestyle information (such as food habits, phenotype information, or individual DNA) suffer from a questionable level of truthfulness and consumer protection in addition to an imbalance between far-reaching promises and contrasting disclaimers. Psychological and behavioral studies indicate that consumer acceptance of a new technology is primarily explained by the end user's rational and emotional interpretation of the technology, including benefits, costs, risks, and uncertainties, as well as moral beliefs. The means of communication influence which of these characteristics have the strongest influence on consumer acceptance. Furthermore, consumer acceptance of personalized nutrition relies on the creation of true value for the consumer and the perception of personal freedom of choice.

\footnotetext{
${ }^{3}$ See in particular the European Commission Web site providing information on EC initiatives in the area of eHealth (Information and Communication Technologies tools and services for health): http:// ec.europa.eu/information_society/activities/health/index_en.htm.
}

From an ethical point of view, consumer protection is crucial, and caution must be taken when putting nutrigenomic-based tests and advice services on the market. Current Internet offerings appear to reveal a need to further guaranty legal certainty by ensuring privacy and the highest standards of consumer protection and safety. Three steps in delivering personalized nutrition services particularly require attention from a legal perspective: gathering personal information from the consumer; using the consumer's data to generate personalized nutrition advice; and providing the advice to the consumer.

Personalized nutrition services are on the borderline between nutrition and medicine. Current regulation of this area is incomplete and undergoing development. This situation entails the need to carefully assess and develop existing rules safeguarding fundamental rights and data protection; at the same time, it is necessary to take into account the sensitivity of the data, the risks posed by each step in their processing, and sufficient guarantees for consumers against potential misuse or abuse. Rather than questionable disclaimers limiting the liability of the providers, compliance with clear criteria targeting varying groups of consumers, should be a prerequisite for any personalized nutrition service.

\section{Reference}

Chadwick R (2004) Nutrigenomics, individualism and public health. Proc Nutr Soc 63:161-166

Charter of Fundamental Rights of the European Union (2010) OJ C 83, 30.3.2010

Communication on PETs (2007) Communication from the Commission to the European Parliament and the Council on Promoting Data Protection by Privacy Enhancing Technologies (PETs) 228 final, 2.5.2007

deCODEme (2011) www.decodeme.com. Accessed 31 October 2011

Data Protections Directive (1995) Directive 95/46/EC of the European Parliament and of the council of 24 October 1995 on the protection of individuals with regard to the processing of personal data and on the free movement of such data, OJ L 281, 23.11.1995 (as amended)

Directive on Electronic Commerce (2000) Directive 2000/31/EC of the European Parliament and of the Council of 8 June 2000 on certain legal aspects of information society services, in particular electronic commerce, in the Internal Market OJ L 178, 17.7.2000

Directive on Privacy and Electronic Communications (2002) Directive 2002/58/EC of the European Parliament and of the Council of 12 July 2002 concerning the processing of personal data and the protection of privacy in the electronic communications sector, OJ L 201, 31.7.2002 (as amended)

Görman U et al (2012) Do we know enough? A scientific and ethical analysis of the basis for genetic based personalized nutrition, this issue of Genes and Nutrition [Epub ahead of print]

Human Genetics Commission (2003) Genes direct: ensuring the effective oversight of genetic tests supplied directly to the public. http://www.dh.gov.uk/prod_consum_dh/groups/dh_digitalassets/ @dh/@en/documents/digitalasset/dh_4068216.pdf. Accessed 25 November 2011 
Interleukin (2011) www.ilgenetics.com. Accessed 31 October 2011

IVDD (1998) Directive 98/79/EC of the European Parliament and of the Council of 27 October 1998 on in vitro diagnostic medical devices, OJ L 331, 7.12.1998 (as amended)

MDD (1993) Council Directive 93/42/EEC of 14 June 1993 concerning medical devices, OJ L 169, 12.7.1993 (as amended)

Misleading and Comparative Advertising Directive (2006) Directive 2006/114/EC of the European Parliament and of the council of 12 December 2006 concerning misleading and comparative advertising (codified version), OJ L 376, 27.12.2006

Navigenics (2011) www.navigenics.com. Accessed 31 October 2011

Nordgren A, Juengst ET (2009) Can genomics tell me who i am? Essentialistic rhetoric in direct-to-consumer DNA testing. New Genet Soc 28:157-172

Nordgren A (2012) Neither as harmful as feared by critics nor as empowering as promised by providers: risk information offered direct to consumer by personal genomics companies. J Community Genet [Epub ahead of print]

Proposal for a General Data Protection Regulation (2012) Proposal for a Regulation of the European Parliament and the council on the protection of individuals with regard to the processing of personal data and on the free movement of such data (General Data Protection Regulation) COM(2012) 11 final, 25.1.2012

Ronteltap A, Van Trijp JCM, Renes RJ, Frewer LJ (2007) Consumer acceptance of technology-based food innovations: lessons for the future of nutrigenomics. Appetite 49:1-17

Ronteltap A, Van Trijp JCM, Renes RJ (2009) Consumer acceptance of nutrigenomics-based personalised nutrition. Br J Nutr 101: 132-144

Ronteltap A, van Trip H, Berezowska A, Goossens J (2012) Nutrigenomics-based personalised nutritional advice: in search of a business model? Genes Nutr Online First 19 August 2012
Services Directive (2006) Directive 2006/123/EC of the European Parliament and of the Council of 12 December 2006 on services in the internal market, OJ L 376, 27.12.2006

Sjöberg L (2005) Gene technology in the eyes of the public and experts-moral opinions, attitudes and risk perception. Working paper series in business administration 2004:7 Stockholm School of Economics. http://swoba.hhs.se/hastba/papers/hastba2004_ 007.pdf. Accessed 25 November 2011

Stewart-Knox BJ, Bunting BP, Gilpin S et al (2009) Attitudes toward genetic testing and personalised nutrition in a representative sample of European consumers. Br J Nutr 101:982-989

Unfair Commercial Practices Directive (2005) Directive 2005/29/EC of the European Parliament and of the Council of 11 May 2005 concerning unfair business-to-consumer commercial practices in the internal market and amending council directive 84/450/EEC, Directives 97/7/EC, 98/27/EC and 2002/65/EC of the European Parliament and of the Council and Regulation (EC) No 2006/ 2004 of the European Parliament and of the Council ('Unfair Commercial Practices Directive'), OJ L 149, 11.6.2005

US Government Accountability Office (2006) Nutrigenetic testing: tests purchased from four web sites mislead consumers. www. gao.gov/new.items/d06977t.pdf. Accessed 31 October 2011

US Government Accountability Office (2010) Direct-to-consumer genetic tests: misleading test results are further complicated by deceptive marketing and other questionable practices. www. gao.gov/new.items/d10847t.pdf. Accessed 31 October 2011

Wendel S, Ronteltap A, Dellaert BGC, van Trijp JCM (2009) Service value chains to support knowledge-based personalized recommendations. Adv Consum Res 36:855

23andMe (2011) www.23andme.com. Accessed 31 October 2011 